\title{
Incursões sobre Avaliação Aberta ${ }^{1}$
}

\author{
Incursions about Open Evaluation
}

\author{
Joana Coeli Ribeiro Garcia \\ Doutora em Ciência da Informação \\ Universidade Federal da Paraíba \\ nacoeli@gmail.com
}

\section{Resumo}

Focaliza a criação do periódico científico e o início do século XVI época em que o conhecimento era discutido em praça pública (open review) e por decisão dos inquisidores (avaliadores) os autores eram aprisionados até mudar (ou não) de ideia. O periódico foi primeiro entregue aos editores de livros que aceitaram o intento avizinhando sua socialização, a ampliação em quantidade economicamente rentável até ser patrocinado por editoras comerciais e universitárias. Nessa travessia a ideia de blind review surge e se consolida. Embora a ciência aberta conte a partir dos séculos XX e XXI com tecnologias aptas a ajudar a ciência a resolver problemas: tornando a comunicação mais rápida entre os indivíduos; conhecimento disponível para os registros científicos; transformações dos registros científicos armazenados e consultados, e acesso aberto, a open review que ofereceria mais qualificação, ainda não conquistou maior espaço na comunicação científica a despeito de editores, autores e avaliadores a defenderem. A avaliação em sistema aberto convém à ciência nessa condição, embora não haja unanimidade na comunicação científica da possibilidade de uso generalizado de open peer review (OPR). $\mathrm{O}$ artigo, fomenta argumentações, não necessariamente fornecendo todas as respostas, mas, atingindo o objetivo em favor da avaliação aberta, nos tempos hodiernos.

\section{Palavras-chaves}

Avaliação aberta. Open peer review. Open review. Comunicação científica. Ciência Aberta.

\section{Abstract}

It focuses on the creation of the scientific journal and the 16 th century when knowledge was discussed in the public arena (open review) and by decision of the inquisitors (evaluators) the authors were imprisoned until they changed (or not) their minds. The periodical was first handed over to book publishers who accepted the intent as it approached its socialization, the expansion in economically profitable quantity until it was sponsored by commercial and university publishers. In this journey, the idea of blind review arises and consolidates. Although open science has from the 20 th and 21st centuries onwards technologies can be able to help science solve problems: making communication between individuals faster; knowledge available for scientific records; transformations of scientific records stored and consulted, and open access, the open review that would offer more qualification, has not yet conquered space in scientific review that would offer more qualification, has not yet conquered space in scientific communication, despite editors, authors and reviewers defending it. Evaluation in an open system suits science in this condition, although there is no unanimity in scientific

\footnotetext{
${ }^{1}$ Este artigo possui versão publicada em pré-print e foi avaliado na modalidade de revisão por pares aberta com identidades reveladas. Revisor A: Eloisa Principe (21/11/2021); Revisor B: Lilian Nassi-Calò (21/12/2021)
}

DOI: $10.28998 /$ cirev.2021v8n3f 
communication about the possibility of widespread use of open peer review (OPR). This article encourages and supports arguments, not necessarily providing all the answers, reaching the objective in favor of open evaluation, in modern times.

Keywords

Open peer review. Open review. Scientific communication. Open science.

\section{PONTO DE PARTIDA}

Ciência Aberta ou open science é termo com o qual convivemos desde fins do Século $X X$, focalizando possibilidades de maior e melhor compartilhamento de informações. Conta com conhecimento enquanto elemento primordial para sua criação e ampliação, induzindo ao aprofundamento e sistematização adquiridos via identificação, observação, pesquisa, explicação e explicitação do fenômeno de eventos, de categorizações formuladas metodicamente, analisado e aceito sob aval da comunidade que participa de todo o processo, inclusive de sua disponibilização (SHINTAKU; SALES, 2019).

Fecher \& Frieske (2014) citam que a open science cobre em amplitude o futuro da criação e da disseminação da ciência, tendo em vista que as demandas eram publicizadas antes da internet e da era digital. Além das premissas para sua existência conta com elementos necessários e integrantes da abertura da ciência convencionados como pilares: acesso aberto, dados abertos, avaliação aberta por pares (em princípio significando que autor e avaliador se conhecem, existindo reciprocidade entre ambos). Seguem-se demais pilares: ciência cidadã, código aberto, caderno de notas de laboratório aberto, recursos educacionais abertos e formação de redes sociais científicas. As tecnologias do pós-guerra disponibilizam, evoluem e remetem para o simples "pensar em algo" e encontrar respostas em smartphones! Os autores recém citados Fecher \& Frieske acrescentam à Ciência Aberta escolas de pensamento e de objetivos com perspectivas de escola democrática tornando o conhecimento gratuito a todos; escola pragmática que abre o processo de sua criação; escola infra estrutural que disponibiliza aos cientistas, plataformas, ferramentas e serviços; a escola pública que possibilita acessibilidade da ciência aos cidadãos; e finalmente a escola da métrica que desenvolve medidas alternativas e de impacto científico.

As escolas se complementam. No entanto, a pragmática apresenta-se como a mais indicada neste artigo, tendo em vista especificar a ampliação do processo, evento que se verifica no tempo e no espaço da história, incluindo-se nos últimos períodos a colaboração das ferramentas on-line para a open science. Cada uma das escolas, per si ou reunidas, oferecem possibilidades e aspectos para o avanço e constituição da ciência aberta, pelo que se entende que seria impossível pensá-la sem ajuizá-la nesses moldes.

Este artigo reúne, resume e discute aspectos do contexto histórico da avaliação aberta considerando episódios a partir da segunda Inquisição. Detém-se na oficialização da criação do periódico científico, e na discussão no Círculo de Hartlib, privilegiando ocorrências da avaliação aberta. Perpassa pela criação, disponibilização do computador na Segunda Guerra mundial, e de sua utilização para ampliar o acesso aos serviços, bem como a utilização das tecnologias de informação e comunicação (TIC), conduzindo até a Ciência Aberta visto que por ela e suas consequências o mundo não mais se repetirá.

A despeito do que está posto e da quantidade de textos selecionados e disponíveis via comunicação científica, perpassa o impresso e alcança o digital com variadas possibilidades de acessar tais informações. Embora ainda não haja unanimidade ao menos na comunicação científica - em especial na publicação de periódicos - da possibilidade de uso genera- 
lizado de open peer review (OPR), o que conduz a alguns questionamentos. Por que ao se criar o periódico científico com outra forma de avaliação - blind review - não se manteve a avaliação aberta, antes existente? Por que, recentemente diante das críticas feitas à revisão cega, não se permite / adota e convive com os dois formatos, oferecendo aos autores a oportunidade de decidir como desejam ser avaliados?

Para responder aos questionamentos considera-se seleção da literatura tomando-a como básica para atender às perguntas que conduzem a atingir, fomentar e respaldar as argumentações, não necessariamente fornecendo todas as respostas, mas em favor da avaliação aberta, historiar a partir dos antecedentes até aos argumentos da Ciência Aberta nos tempos hodiernos.

\section{ANTECEDENTES DA AVALIAÇÃO ABERTA}

É possível considerar que na época em que ideias e conhecimento eram discutidos em praça pública, a qualquer discordância das falas dos inquiridos dos preceitos dominantes geralmente da Igreja, os que permaneciam com o mesmo pensamento, sem convivência pacífica, ou contrário aos cânones restava-lhes o aprisionamento, o calabouço, ou a queima em fogueiras. A história denomina de Inquisição ao julgamento e condenação sumária de hereges e feiticeiros acusados de crimes contra a religião e a ciência.

Embora haja relação entre religião e ciência, os conflitos ampliam-se quando os dogmas são colocados a prova impondo-se sobre fatos, teorias científicas e explicações naturais contradizendo preceitos consolidados. Ciência e religião adequam-se, com alternâncias de concepções filosóficas, contextos políticos, socioeconômicos e novas acepções, necessitando obediência a formalidades dentre elas a avaliativa. Mas nem sempre ocorreu nesse formato ou pôde ser analisado e verificado pelo ângulo de quem discordava abertamente ou oferecia explicações convergentes para ampliar o conhecimento e favorecer a ciência em possibilidade ao que estava posto.

Há versões tanto na Inquisição medieval; entre os séculos XIII e XIV, quanto na Inquisição moderna, concentrada principalmente em Portugal e Espanha entre os séculos XV e $\mathrm{XIX}$ em que os autores camuflavam, as vezes o objeto do saber e noutras as ideias que defendiam, objetivando não serem submetidos a julgamento. Ainda que religião e ciência empreguem métodos diversos ou similares para questões igualmente diferentes, a atenção deve ser dirigida ao fato de que tal discussão muitas vezes ocorria em praça pública com participação dos habitantes das cidades constituindo claques quase sempre contrárias às respostas oferecidas pelos questionados.

Menocchio, protagonista de O Queijo e os vermes: o cotidiano e as ideias de um moleiro perseguido pela Inquisição, autoria de Carlo Ginzburg, foi prisioneiro por duas vezes. Com visão materialista afirmava que "se diz que o homem é formado à imagem e semelhança de Deus, e no homem existe ar, fogo, terra e água, e disso segue que ar, terra, fogo e água são Deus" (Ginzburg, 1987, p.122). Ao ser inquirido, cada vez trocava as palavras, continuando com o raciocínio imperturbável, afirmando sempre com base na interpretação do que havia lido (mais ou menos 60 livros). Cada vez que respondia ao inquisidor sobre de onde retirava tais ideias, repetia que havia lido, não lembrava onde, mas tudo provinha de sua cabeça.

Enquanto isso, o pai da ciência moderna, Galileu Galilei (1564-1642), convence-se que a Inquisição se encontra menos rígida por volta de 1623, quando Maffeo Barberini (1568-1644), seu amigo, torna-se o Papa Urbano VIII, da Igreja Católica. E ele, Galilei (2009 e 
2011) acreditando estar protegido pela amizade com o superior, torna público seus `Diálogos em torno dos dois máximos sistemas do mundo' no qual confronta o aristotélico-ptolomaico com o copernicano, afirmando que a terra não é o centro do universo, ela gira em torno de si e ao redor do sol. Assim, o astro ao centro é o sol. A defesa feita por Galileu confronta os preceitos em objeção às pregações da Igreja e da ciência. Tanto é assim que o Papa que era seu amigo, não o reconhece como tal, não o socorre, nem o favorece, e Galileu é aprisionado. Os inquisidores, que escrutinaram o trabalho como peer review, se ativeram somente aos questionamentos dogmáticos (MENEGHINI, 1998).

Contemporâneo do período e conhecedor desses revezes, René Descartes (15961650) publica em 1637 o discurso do método, explicitando a dubiedade em que se encontrava com questões controvertidas para os doutos, com os quais não deseja se indispor.

[...] temendo não poder colocar em meu discurso tudo o que tinha no pensamento, resolvi acrescentar alguma coisa acerca do sol e das estrelas fixas, já que deles procede quase toda luz; acerca dos céus porque a transmitem; de planetas, dos cometas e da Terra, porque são ou coloridos, ou transparentes, ou luminosos; e, por fim, do homem, porque é o espectador (DESCARTES, 2006, p. 79-80)

[...] pensei que as ciências dos livros, ... tendo se formado e crescido aos poucos com as opiniões de muitas diversas pessoas, não se acham tão próximas da verdade quanto os simples raciocínios que um homem de bom senso pode fazer naturalmente com as coisas que se apresentam (DESCARTES, 2006, p.48-49).

Descartes também desejou referir a obra: O mundo ou tratado da luz, que havia iniciado, tendo desistido após a condenação de Galilei. Porém acreditava que suas ideias não eram somente dele, que devia haver outras pessoas que as tinham e refletiam sobre elas, até melhor que ele.

\subsection{A Revisão Aberta no Periódico Científico}

Nesse clima em que tanto fazia ser cientista ou simples homem do povo, todos deviam seguir os ditames da religião e da ciência, utilizando com parcimônia, ou camuflando com astúcia, o que conheciam para não entregar as pedras do tabuleiro de uma vez. Tal situação foi adotada tanto por Descartes quanto por Menocchio. Do contrário estariam fadados a perecer numa prisão ou queimar vivo na fogueira.

Também no período em que se criam os periódicos científicos, o conhecimento se apresenta abertamente avaliado por correspondências mantidas entre autor e avaliador, conhecidos entre si. Para Ranalli (2011) a revisão por pares tem início em 1663 quando oficialmente se aprova a resolução para publicação de livros, exigindo que cada livro fosse revisado por pelo menos dois membros da Royal Society. Porém, diversamente, ao entregar o periódico Philosophical Transactions para publicação junto à editora de livros, a indicação era que os avaliadores não fossem membros da sociedade científica, porquanto suas ideias eram públicas, conhecidas entre os membros. Por via de consequência seria bem mais fácil identificar os referees. Para não causar mal-estar entre eles, melhor seria solicitar avaliação a alguém que não pertencesse aos quadros da Royal Society.

Outrossim, Ranalli (2011) relembra citação do bispo protestante, educador, cientista e escritor checo Jan Amos Komensky (1592-1670) que ao publicar Via Lucis exorta e desafia os membros da Royal Society a publicar suas afirmações de verdade de forma aberta à crítica, à reprodução e à verificação por qualquer leitor. As ideias de Comenius ou Komensky, 
para sustentar tal modelo de avaliação, estavam calcadas nos sermões religiosos, em que o bispo fazia sua pregação pedagógica: Será um precedente admirável a encorajar aqueles que estão à frente da sociedade humana no Estado, ou das consciências dos homens da Igreja a agirem da mesma maneira, seguindo de fato o exemplo dos Apóstolos que não temeram em submeter todas as suas doutrinas ao escrutínio e julgamento do mundo (COMENIUS [1668] 1938, p. 22-23 apud RANALLI, 2011, p.13). Comenius adota o método empírico de explorar o mundo em oposição às verdades impostas pelo ensino medieval, sua didática seguia três momentos: a arte de ensinar, por que se ensinar e por que aprender (BURKE, 2020).

O Século XVII compreende manifestações artísticas na literatura, pintura, arquitetura e música que foram produzidas entre o final do século XVI e início do XVIII inclusive pela revolução científica. Esta ocorre a partir de quando Galileu Galilei (1564-1642) e outros pensadores que lutavam pela autoridade da ciência iniciam suas descobertas. A ciência até então atrelada à filosofia, separa-se e apresenta conhecimento estruturado e prático, prevalecendo ciência e religião limitadas a identificar o que existia ao alcance dos olhos.

Na Pré-história da revisão por pares, Ranalli (2011) refere-se a Kronick (1990) ao afirmar que os antecedentes dessa temática datam do século XVII. Há, contudo, semelhanças interessantes e instrutivas na maneira como os editores definiram, exerceram prerrogativas e responsabilidades. Preocupações, ideias e práticas se relacionam ao que hoje chamamos de revisão paritária ou arbitragem. Para Meadows (1999) a Royal Society seguiu estes antecedentes quando se responsabilizou pelo Philosophical Transactions em 1752.

Também Burnham (2011) questiona a inexistência de relatos históricos da evolução da revisão por pares, afirmando que os periódicos biomédicos surgem somente no século $\mathrm{XIX}$, seguindo o modelo do jornalismo mais geral e os editores de periódicos que atuavam como educadores. Os procedimentos de revisão editorial por pares ocorrem de forma irregular visto que, os conselhos editoriais foram transmitidos repetidamente de periódico a periódico e desenvolvidos sem organização. Referências de textos individuais ocorreram do início a meados do século XIX, mas a institucionalização do processo ocorreu no século XX e a prática da revisão editorial por pares se generalizou somente após a Segunda Guerra Mundial (BURNHAM, 2011).

Assim é que contexto e história admitem que desde os primórdios da comunicação científica a avaliação se realizava de formas variadas e em formato aberto, quando o autor conhecia o avaliador e vice-versa. Com facilidades fornecidas ao permitir que um mesmo conselho editorial pertencesse a vários periódicos, por uma rede de comunicações ou, se houvesse entraves que comprometessem a atuação, permitia-se à ciência formalizar os resultados da pesquisa por algum suporte que preservasse e estabelecesse a prioridade e autoria da descoberta.

Como referido sobre o Philosophical Transactions, seu editor Henry Oldenburg permite a continuidade da avaliação aberta, com aprovação constante na publicação, na divulgação e de forma subliminar, na inclusão do subtítulo em que explicita (dando alguns resultados dos atuais empreendimentos, estudos e trabalho dos engenhosos em muitas partes consideráveis do mundo). Em razão de que, para Oldenburg os aspectos da avaliação dos sistemas sigilosos ou secretos deveriam ser esclarecidos e desvendados sugerindo ampla cobertura. Outrossim, considera possibilidade de divulgação oferecida a maior número de leitores, com intervalos de tempo menores, adequada a período específico e quantidade de pessoas tomando conhecimento ao mesmo tempo do que continham. (MEADOWS, 1999, p. 6-7).

Desta maneira entende-se que o periódico equivale a mercadoria disponibilizada comercialmente e por consequência amplia-se o poder do editor em dois ângulos, pela expec- 
tativa de lucro financeiro e pela tomada de decisão sobre os destinos do produto, qual seja dos artigos, dos autores e dos revisores de toda publicação (BOLANO, KOBASHI, SANTOS, 2006).

\section{OS SÉCULOS XX e XXI}

As novidades consideradas representativas da atualidade surgem em meados do Século XX quando durante a Segunda Guerra Mundial os computadores revolucionam a pesquisa, a ciência e a comunicação científica. No entanto, a utilização de informações e o acesso a elas resultantes das possibilidades da tecnologia computadorizada e dos canais de comunicação não atingiram os periódicos da mesma forma e ao mesmo tempo.

Vannevar Bush (1890-1974), ao conhecer o computador durante a guerra, escreve o célebre: As we may think, título do relatório ao Presidente Roosevelt em que explicitava suas impressões sobre uma máquina que trabalhava como se repetisse as funções do cérebro, ou seja, sempre associando informações para amplia o conhecimento. O Memex (Memory Extender) conectava coisas aparentemente díspares, exatamente como o cérebro humano, justificando a perfeita sintonia do título do relatório. Bush especula sobre o que a ciência e a tecnologia poderiam trazer à humanidade nos tempos de paz depois do que havia sido feito durante a guerra. No clássico texto, Bush (1945) insiste com o Presidente dos Estados Unidos sobre pessoal com qualificações para conduzir a nova área, bem como a necessidade de organização das informações produzidas durante a ll Guerra e de uma teoria que baliza a ciência.

Kripka; Viali e Lahm (2016) sintetizam as contribuições para à ciência e à tecnologia, indicando o hipertexto e o Memex como revolucionários e listam os seguintes argumentos de Bush (1945): 1) a ciência tornou a comunicação mais rápida entre os indivíduos; 2) a grande quantidade dos resultados de pesquisa dificultava o conhecimento e impedia o real uso dos registros científicos; 3 ) a fabricação urgente e imperiosa de instrumentos que possibilitam as transformações dos registros científicos; 4) os registros só serviriam à ciência, se pudessem ser armazenados e consultados.

Vannevar Bush não se contentou em somente argumentar. Como físico, sugeriu soluções ou aparelhos para gravação de filmes coloridos; indicou avanços na micrografia; fez combinação da ótica e da redução fotográfica; sobre a criação do microfilme; formas de armazenamento de grandes quantidades de informações em modo reduzido, e da possibilidade de consultá-los de maneira eficiente; registro sem escrita falando diretamente. Além disso o Memex possibilitaria realizar busca por associação, sua ideia inovadora resgatando conhecimentos a semelhança do que faz a memória, podendo impulsionar resultados para o avanço da ciência. Em 1965 Ted Nelson cria o hipertexto, que ao ser caracterizado por Tim Berners Lee como world wide web - WWW, permite ao leitor seguir links e chegar ao documento original, partindo de uma citação curta. Simples assim como afirmaram Kripka; Viali e Lahm (2016).

Se antes da II Guerra Mundial havia dificuldades, estas foram sanadas com o desenvolvimento de sistemas que oferecem condições tecnológicas para adotar e avaliar em sistema aberto como convém a Ciência Aberta. (KRIPKA; VIALI; LAHM, 2016). É verdade que o incremento de títulos de periódicos amplia as obrigações do editor cada vez mais facilitadas pelas atualizações via tecnologias computacionais. Dentre essas possibilidades está a produção de periódicos científicos que encontra aliado junto ao Open Journal Systems (OJS), software livre criado em 1998, por John Willinsky, da Universidade de Stanford. 
Segundo dados do Google de agosto de 2021 o OJS oferece gestão de 17.300 .000 periódicos acadêmicos revisados por pares dos quais: 48.038 títulos em textos completo; 130 bases de dados de referências e resumos; 41 bases de dados estatísticas; 64 bases de teses e dissertações; 48 obras de referência incluindo dicionários especializados, acervos de bibliotecas, compêndios, bancos de dados e ferramentas de análise. As versões atualizadas e disponibilizadas em 2021 - 3.3 Open Journal Systems (OJS), Open Monograph Press (OMP) e Open Preprint Systems (OPS) oferecem condições a que se realize processo editorial mais intuitivo e dinâmico. OJS / OMP / OPS 3.3 incluem dentre as mudanças: melhor usabilidade e acessibilidade; alterações no painel e nos menus de navegação; melhorias na gestão de submissões; mudanças na terminologia do tipo de revisão; aprimoramentos para a gestão e comunicação de utilizadores; novos recursos para revistas multilíngues. É fácil perceber que algumas delas estão consideradas com direcionamento a open peer review.

A atualização permite adotar blind review, double blind review, em que autores e avaliadores são desconhecidos entre si. Mas, também a open peer review pode ter avaliadores sugeridos por autores, permanecendo o editor como mediador para qualquer situação. Ao conhecimento tecnológico cabe favorecer a tempestividade, quantidade, qualidade e disseminação do periódico.

A Ciência Aberta conta com pilares como antes referidos, dentre eles o acesso aberto e a avaliação aberta que oferecem maior qualificação e favorecem a que autores e avaliadores defendam convivência com quantas novas formas de avaliação existirem e, retorno ao que historicamente foi concedido e dispensado à comunicação científica. Há algumas condições aceitáveis de ter ocorrido no passado, porquanto as formas possíveis se restringiam ao presencial, às cartas, ou ao impresso, ainda que oferecendo possibilidade de reconhecer que autor e referee se conheçam um ao outro.

\subsection{Características da Avaliação Aberta}

Retoma-se o conceito de avaliação aberta ou open peer review (OPR), sob o direcionamento de Emily Ford (2013), ao reunir literatura das áreas de humanidades e ciências sociais afirmando que não há definição única que seja ao mesmo tempo aceitável por pesquisadores, cientistas e pela comunidade de publicação. Resumidamente concebe OPR como um processo que permite a identificação de autores e avaliadores, conhecidos entre si e do público que acessa os periódicos. Os revisores podem continuar anônimos, entretanto seus relatórios devem ser publicados, com o que eles consideram aceitável e íntegro. É um processo transparente que permite comentários também pelos leitores, podendo estes serem formalmente colocados ao lado dos formulados pelos avaliadores.

Sobre as características da avaliação aberta, considera-se a tipologia sumarizada por Silva, Garcia e Targino (2021) a partir dos autores nomeados.

- signed review / avaliação assinada - o parecer ou as opiniões do avaliador são divulgadas quando da publicação dos artigos ou enviadas ao autor, conforme sugere Monsen e Horn (2007). Segundo Ross-Helauer (2017) esta proposição além de reduzir o tempo da avaliação, contribui para o avanço da própria ciência tanto quanto da comunicação.

- disclosed review / avaliação tornada pública - avaliadores e autores conhecem as identidades um do outro; descartam-se relatórios que acumulam espaços, permitindo conhecimento público e ampliado da avaliação (ROSS-HELAUER; DEPPE; SCHMIDT, 2017). 
- editor mediated review / avaliação mediada pelo editor - a avaliação é mediada pelo editor entre autores e avaliadores e vice-versa. Os envolvidos sabem quem disse o quê, existindo a possibilidade de discussão, consenso e acordo entre eles.

- transparent review / avaliação transparente - avaliação aberta à comunidade científica e / ou ao público-leitor, ou seja, originais, comentários dos autores e / ou respostas dos autores aos revisores são disponíveis aos interessados. Identidades, avaliações e respostas dos autores são conhecidas com a publicação do artigo (FORD, 2013).

- crowdsourced review / avaliação pública realizada por grupo ampliado de juízes onde membros da comunidade podem contribuir com opiniões. Autores como Brabham (2012); Estellés-Arolas e Gonzales-Ladrón-De-Guevara (2012) e Ford (2013) incluem neste formato termos denominados pela própria ciência aberta, tais como: ciência cidadã; sabedoria das multidões; inteligência coletiva; redes de colaboração e pesquisa participativa.

- pre-publication review / avaliação pré-publicação - avaliação precedente a publicação do artigo, em geral, em espaço público, com servidor de pré-impressão. Situam-se aqui os preprints, com a diferença que o artigo ainda não foi submetido a um periódico, portanto, considera-se como uma fase antecedente. Somente após o escrutínio o artigo é encaminhado ao periódico. Poschl (2012) e Spinak (2016) concordam entre si que os riscos ou desvantagens desse modelo são mínimos, superados por uma série de vantagens.

- synchronous review / avaliação síncrona - avaliação paralela à edição do artigo; Ford (2013) considera análise realizada em complementação à publicação formal.

- post-publication / avaliação pós-publicação - avaliação posterior à publicação do artigo, incluindo comentários em posts de blogs. Este formato oferece tanto comentários favoráveis quanto desfavoráveis. Na verdade, deixa ao leitor o encargo por ser o fiel da balança, na escolha de usar ou não usar posteriormente o artigo como elemento de sua revisão de literatura. Mas isto ocorre com tudo que é publicado. Ao leitor / usuário compete decidir entre as possibilidades de acordo com as motivações e os interesses relacionados a sua pesquisa.

Há indícios de que os editores começam a vislumbrar atitudes diferenciadas em seu métier, ao se permitirem refletir sobre open peer review. Assim como há periódicos que são criados disponibilizando as duas possibilidades de avaliação, enquanto há outros que ao longo do tempo, passam por mudanças, incluindo-as no processo de avaliação aberta. Muitos cientistas acreditam que atravessamos um período de transição, em que a OPR se torna realidade para alguns periódicos: Nature Communications, Peer J, BMJ e F1000 Research.

Detalha-se o exemplo de Encrucijadas: Revista Crítica de Ciências Sociais, criada em junho de 2011, na Espanha, e que disponibiliza aos autores formas alternativas ao sistema de revisão duplo cego, apostando também no modelo de avaliação aberta apoiada em dois aspectos. Primeiramente, porque a OPR recorre a mais cuidados e por via de consequência torna-se menos frágil, exige primor do avaliador, inclusive rompe a clássica relação autor / avaliador. Em segundo lugar, para questionar se o sistema aberto garante avaliações rigorosas, vislumbrando a perspectiva crítica que a revista contém em sua denominação.

No exemplo de Encrucijadas, os avaliadores conhecem a identidade dos autores, estes ao receberem o retorno dos textos conhecem identidade e afiliação dos avaliadores, enquanto o comitê editorial mantém e garante uma rede de pessoas e instituições. Entre 2011 e 2016, o periódico recebeu 236 proposições de artigos dos quais 93 passaram pela fase de ser ou não aceito pelos pares do Comitê Editorial, sendo 12 recusados, e 81 efetivamente aceitos e publicados, após avaliação. Significa que ao passar pela revisão aberta do par, não necessariamente quer dizer indicações de aprimoramento do texto, no sentido de atingir a 
etapa de aceite. No caso da revista espanhola, mesmo supondo que os pares foram polidos e gentis, não houve o que podia ser melhorado, culminando na recusa de $65,7 \%$ dos artigos. $\mathrm{E}$ no período do estudo, acatou 34,3\% artigos para publicação. Os autores do artigo Chirino et al. (2017), desejam que a avaliação aberta se oriente por crítica construtiva, de modo que, autores, avaliadores e editores creditem à avaliação possibilidades de melhoria, redundando em qualidade da publicação.

Em 2018 a Unidade de Recursos de Información Científica para la Investigación do Digital.CSIC, terceira maior instituição pública dedicada à pesquisa na Europa, realiza pesquisa sobre revisões abertas e modelos alternativos, no Digital.CSIC. O estudo conduzido por Bernal e Román-Molina (2018), técnicos do referido Conselho, resulta em grande quantidade de dados. Resumidamente: responderam 158 pesquisadores do CSIC, cuja faixa etária varia de 25 a mais de 60 anos. Destes, $60 \%$ percebem benefícios na revisão aberta por pares, sendo $40 \%$ deles favoráveis a abertura total do módulo POR como meio para convidar os pesquisadores à revisão aberta em seus trabalhos; $50 \%$ concordam em revelar a identidade dos avaliadores, o que ajudaria a reduzir conflitos de interesse. Os $40 \%$ contrários, referem a falta de objetividade e de espírito crítico nas revisões, sendo que mais da metade destes, ou seja, $54 \%$ estão satisfeitos com o sistema dominante. $88,6 \%$ consideram priorizar a produtividade científica, escolhendo como forma preferida o duplo cego. Entretanto 83,5\% informam que continuariam a publicar em periódicos que adotem revisão aberta; $74,1 \%$ sugerem estender às revistas todas as tipologias de revisão de pesquisa.

A British Medical Journal conceituada publicação sobre medicina do Reino Unido, com mais de 140.000 associados, gerida pelo BMJ Group junto a várias dezenas de títulos de periódicos sobre diferentes especialidades médicas, propaga acreditar na facilidade e rapidez da disseminação da pesquisa porquanto beneficia a todos com rigorosa avaliação, grande citação e disseminação. Usa a open peer review desde 1999, quando o editor Richard Smith administra a mudança do sistema blind para open. Em suas argumentações ele relata que os avaliadores conheciam os nomes dos autores, mas o inverso não ocorria. Isto amplia seus argumentos sobre a revisão ser lenta, cara, esbanjadora de tempo acadêmico, subjetiva, propensa a vieses, no mais das vezes abusada, difícil na detecção de erros e quase inútil para solucionar fraudes. Usa inclusive palavras do seu antecessor ao admitir que a ciência se afasta do anonimato e ele, Richard Smith afirma que o poder vem da responsabilidade do cientista enquanto juiz que deve ser crítico construtivo e que os autores são favoráveis à revisão aberta por pares (SMITH,1999).

No Brasil, pesquisa realizada com editores de periódicos da Ciência da Informação (Cl) ano 2017, resulta que estes se apresentam defendendo os dois lados da moeda. Tanto há os que são favoráveis a open peer review, quanto os que acreditam que a OPR pode atuar em prol da qualidade das revistas. No entanto, quando questionados se a adotariam são dúbios em suas respostas, afirmando duvidar do potencial das tecnologias direcionadas à editoração. De outra parte, há referee que se manifesta favorável a OPR, porém nunca recebeu do editor submissão para avaliar nessa condição, ignorando se houve proposição aos autores, permanecendo a não resposta do editor e a incerteza do avaliador (GARCIA; TARGINO, 2017). Ainda convivemos com indefinições em termos gerais na área. Uma revisão nas políticas dos títulos de periódicos da área, resulta em três ou quatro que aceitam e utilizam o preprint como forma de receber comentários anteriores aos pareceres dos avaliadores designados pelos conselhos editoriais.

A Ciência e Saúde Coletiva, periódico mensal editado pela Fundação Oswaldo Cruz (Fiocruz) recentemente, convoca autores para adotar três tipos de inovações: 1) colocar 
o manuscrito em um servidor de preprint. No SciELO ele recebe um Identificador de Objeto Digital - o DOI com dupla função identificar a publicação e conceder ao artigo mais velocidade para ser aceito; 2) compromisso de disponibilizar dados de pesquisa em formato aberto, também com repositório no SciELO; 3) disponibilizar os nomes dos responsáveis pela avaliação e/ou divulgar os pareceres com ou sem identificação (MINAYO, M. C. S.; GOMES, R; SILVA. A. A. M. 2020).

No relatório de avaliação tornado público no artigo de Tennant et al. (2017) encontra-se o que se segue. Uma perspectiva multidisciplinar sobre inovações emergentes e futuras na revisão por pares [versão 3; revisão por pares: 2 aprovados]. F1000Research, 6, https://doi.org/10.12688/f1000research.12037.3, nos seguintes termos: Status do árbitro: indexado; Relatório do Árbitro: 10.5256 / f1000research.14133.r27485, David Moher, Center for Journalology, Clinical Epidemiology Program, Ottawa Hospital Research Institute, Ottawa, ON, Canadá, 10 de novembro de 2017, versão 2, indexado; Relatório do Árbitro: 10.5256 / F1000research.14133.r27486, Virginia Barbour, Queensland University of Technology (QUT), Brisbane, Qld, Austrália, 13 de novembro de 2017, versão 2, indexado; Informações sobre a subvenção: TRH foi apoiado por financiamento do projeto OpenAIRE 2020 da Comissão Europeia H2020 (convenção de subvenção: 643410, chamada: H2020-EINFRA-2014-1). Os custos de publicação deste artigo foram financiados pelo Imperial College London. Os financiadores não tiveram nenhum papel no desenho do estudo, coleta e análise de dados, decisão de publicar ou preparação do manuscrito. Talvez divulgação como esta provoque receio na comunidade científica pela exposição sobre o artigo em si, mas também sobre os árbitros.

Pedri e Araújo (2020) em estudo sobre vantagens e desvantagens na literatura sobre OPR, indicam 38 menções para qualidade do tipo comentários mais construtivos, consistentes e coerentes; 17 para ética; 12 para reconhecimento e 9 indicações para transparência. No entanto, na totalidade as desvantagens aparecem com $64,2 \%$ contra $46,7 \%$ de vantagens. Os autores ainda chamam atenção para o diálogo entre autores e avaliadores que evidenciam colaboração e profissionalismo entre eles.

\section{NOVOS QUESTIONAMENTOS}

Neste momento a modalidade de avaliação aberta tem um percurso relatado, faltando, retomar a expressão com a palavra pares. No contexto avaliativo ela significa feita por um semelhante, alguém em condições iguais a quem submete o artigo, pertencente à sua categoria, ou assemelhada. Inexiste a ideia de que haverá complacência com o texto a avaliar, ou que o par se obriga a contribuir com indicações para aprimorá-lo. Nenhum editor, de nenhum periódico, garante isto aprioristicamente, do contrário não haveria artigo recusado. Embora nenhum título de periódico determine, e nenhuma situação de avaliação garanta, seja open peer review, seja blind review, espera-se gentileza e educação ao se dirigir ao congênere.

Ainda assim, Encrucijadas em seis anos recebeu 236 artigos e destes, publicou 86. Isto exemplifica e comprova que nem tudo que um par enquanto autor pensa, escreve e envia a um periódico, é aceito, ou está em condições de ser aprovado. Também pode significar que nem tudo que os pares avaliam o fazem com espírito colaborativo para ajudar a melhorar a produção e acatá-la. Porque não é isto que se espera da avaliação aberta: formalmente, somente os artigos relatados e que estejam em condições de ser aceitos pelos pares, ou a necessitar de alguma complementação com informações atualizadas e novos conhecimentos 
conduzem a ser publicados. Estes são os desejos dos cientistas sejam autores, editores e revisores.

Por outro lado, a single blind review e a double blind review tomam ciência de ideias, conhecem perspectivas de tempos anteriores em que o referee não abandona o compromisso com a ciência ou com os pressupostos que a tornam conhecida e se realiza como ciência, ou seja - avaliada e tornada pública. Como explicitado, a participação dos pares evidencia o diálogo em maior ou menor grau, a colaboração entre membros da comunidade científica, resultando em concordâncias em torno de temas e / ou problemas de pesquisa. Oferece transparência ao processo editorial, melhorando a qualidade das revistas, e pela avaliação, agregando valor ao texto.

Outro fator positivo é que torna o processo transparente, embora, sem assinatura, ou sem identificação (atendendo à blind peer review), que haja opções de envio para autor e editor, apenas para o editor e este envie o teor da avaliação ao autor. Ao enviar o parecer para editor e autor traduz transparência, visto que o autor ao acessar a submissão acessa a avaliação que compõe a decisão editorial.

A despeito de idas e vindas, de quantos se posicionam favoráveis e dos que discordam dos preceitos iniciais da ciência, ou da avaliação aberta, o mundo conhece e sabe que a terra gira em torno de si, num percurso de vinte e quatro horas, ou correspondente a um dia, e em 365 dias ao redor do sol ou um ano. Esperando uma convivência pacífica sem que haja hereges, feiticeiros ou inquisição, ao contrário, permitindo-se que todos possam abertamente se pronunciar.

\section{AGRADECIMENTOS}

Aos editores Dr. Edivânio Duarte de Souza e Dr. Ronaldo Araújo que acataram realizar a avaliação do artigo em formato aberto, antecipando-a pelo preprint no SCiELO. Marcaram tento positivo porquanto, na listagem dos 44 títulos de periódicos brasileiros da Ciência da Informação, somente cinco sugerem e adotam o preprint, estando a primazia e a permissão de publicar as decisões dos avaliadores com a Ciência da Informação em Revista. A decisão dos editores conclama para práticas transparentes de conhecimento que contribuem para o sucesso da Ciência Aberta.

Às avaliadoras/colaboradoras! Momento de reconhecer a avaliação por pares aberta em sua amplitude. Penhorados agradecimentos, considerando-as colaboradoras no artigo, porquanto após a revisão, o mérito deve-se ao esmero e a experiências dignas de menção da Dra. Eloisa Príncipe e da Dra. Lilian Nassi-Calò, cada uma tratando de especificidades, aspectos e detalhes.

\section{REFERÊNCIAS}

BERNAL, I.; ROMAN-MOLINA, J. Encuesta sobre la evaluacion por pares y el módulo "open peer review" de Digital. CSIC, Madrid, jul. 2018.

BOLAÑO, C.; KOBASHI, N.; SANTOS, R. A lógica econômica da edição científica certificada. Encontros Bibli: Revista Eletrônica Biblioteconomia e Ciência da Informação., Florianópolis, 
número especial, p. 119-131, jan./jun. 2006. Disponível em:

https://brapci.inf.br/index.php/res/download/96050. Acesso em: 20 ago. 2021.

BRABHAM, D. C. Motivations for participations in a crowdsourcing application to improve public engagement in transit planning. Journal of Applied Communication Research, Columbia, v. 40, n. 3, p. 307-328, May, 2012. Disponível em: https://www.tandfonline.com/doi/abs/10.1080/00909882.2012.693940. Acesso em: 20 ago. 2021.

BURNHAM, J. C. The evolution of editorial peer review. Journal of American Medical Association, [S. I.], v. 263, n. 10, p. 1323-29, 2011. Disponível

em: https://jamanetwork.com/journals/jama/article-abstract/380937. Acesso em: 17 ago. 2021.

BURKE, P. O polímata: a história cultural de Leonardo da Vinci a Susan Sontag. São Paulo: UNESP, 2020.

BUSH, V. As we may think. The Atlantic Monthly, [S. I.], July,1945. Disponível em: https://www.theatlantic.com/magazine/archive/1945/07/as-we-may-think/303881/. Acesso em: 14 ago. 2021.

CHIRINO, D. M. et al. Potencialidad y viabilidades de los processos de evaluación por pares abierto: el caso de Encrucijadas: Revista Crítica de Ciencias Sociales. Teknocultura, Madrid, v. 14, n. 1, p. 35-56, 2017. Disponível em: https://revistas.ucm.es/index.php/TEKN/article/view/55575. Acesso em: 13 ago. 2021.

DESCARTES, R. Discurso do método. Porto Alegre: L\&amp;PM, 2006.

ESTELLÉS-AROLAS E.; GONZALES-LADRÓN-DE-GUEVARA, F. Towards anintegrated crouwdsourcing definition. Journal of Information Science, Thousand Oaks, v. 38, n. 2, p.117, Mar. 2012. Disponível em: http://www.crowdsourcing-blog.org/wpcontent/uploads/2012/02/Towards-an-integrated-crowdsourcing-definition-Estell\%C3\%A9sGonz\%C3\%A1lez.pdf. Acesso em: 26 jul. 2021.

FECHER, B.; FRIESIKE, S. Open science: one term, five schools of thought. In:BARTLING S.; FRIESIKE, S. (Eds.). Opening Science: the evolving guide on how the internet is changing research, collaboration and scholarly publishing. London: Springer, 2014. Cap. 5.

FORD, E. Defining and characterizing open peer review: a review of the literature. Journal of Scholarly Publishing, Toronto, v. 44, n. 4, p. 311-326, Jul. 2013. Disponível em: https://pdxscholar.library.pdx.edu/cgi/viewcontent.cgi?article=1000\&amp;context=ulib_fac. Acesso em: 11 jun. 2021.

GALILEI, G. Ciencia e fé. São Paulo: Editora UNESP, 2009.

GALILEI, G. Diálogo sobre os dois máximos sistemas do mundo ptolomaico e copernicano. São Paulo: Ed. UNESP, 2011. 
GARCIA, J. C. R.; TARGINO, M. G. Open peer review sob a ótica de editores das revistas brasileiras da Ciência da Informação. In: ENCONTRO NACIONAL DE PESQUISA, EM CIÊNCIA DA INFORMAÇÃO, 18., 2017, Marília. Anais [...]. Marília: UNESP, 2017. p. 1-21. Disponível em: https://brapci.inf.br/index.php/res/v/104007. Acesso em: 20 jun. 2021.

GINZBURG, Carlo. O queijo e os vermes: o cotidiano e as ideias de um moleiro perseguido pela Inquisição. São Paulo: Companhia das Letras, 1987.

KRIPKA, R. M. L.; VIALI, L.; LAHM, R. A. Contribuições de Vannevar Bush para a ciência e a tecnologia, especialmente ao hipertexto. Revista Conhecimento Online, Novo Hamburgo, v. 2, p. 55-68, jul./dez. 2016. Disponível em:

https://periodicos.feevale.br/seer/index.php/revistaconhecimentoonline/article/view/410. Acesso em: 15 jun. 2021.

KRONICK, D. A. Peer review in 18th-century scientific journalism. Journal of the American Medica Association, [S. I.], v. 263, n. 10, p. 1321-22, Mar. 1990. Disponível em: https://jamanetwork.com/journals/jama/article-abstract/380935. Acesso em: 21 jul. 2021.

MEADOWS, A. A. A comunicação científica. Brasília, DF: Briquet de Lemos/Livros, 1999.

MENEGHINI, R. Peer review and society. Ciência e Cultura, [S. I.], n. 50, p.17-18, 1998.

MINAIO, M. C. S.; GOMES, R; SILVA. A. A. M. Convite a você colaborador para aderir a Ciência Aberta. Revista Ciência e Saúde Coletiva, jan. 2020 Disponível em: https://www.cienciaesaudecoletiva.com.br/. Acesso em: 19 jan. 2022.

MONSEN, E. R.; HORN, L. V. Research successful approaches. 30. ed.Illinois: American Dietetic Association, 2007.

PEDRI, P.; ARAÚJO, R. F. Vantagens e desvantagens da revisão por pares aberta: consensos e dissensos na literatura. In: ENCONTRO BRASILEIRO DE BIBLIOMETRIA E CIENTOMETRIA, 7., 2020, Salvador. Anais [...]. Salvador: UFBA, 2020. p. 79-86. Disponível em: https://brapci.inf.br/index.php/res/v/148865. Acesso em: 26 jun. 2021.

POSCHL, U. Multi-stage open peer review: scientific evaluation integrating the strengths of traditional peer review with the virtues of transparency and self-regulation. Frontiers in Computational Neuroscience, Rockville, v. 6, n. 33, p.1-16, July. 2012. Disponível em: https://www.ncbi.nlm.nih.gov/pmc/articles/PMC3389610/. Acesso em: 25 jul. 2021.

RANALLI, B. T. A Prehistory of Peer Review: Religious Blueprints from the Hartlib Circle. Spontaneous Generations: A Journal for the History and Philosophy of Science, Ontário, v. 5, n. 1, p. 12-18, 2011. Disponível em:

https://spontaneousgenerations.library.utoronto.ca/index.php/SpontaneousGenerations/ar ticle/view/14973. Acesso em: 21 jun. 2021. 
ROSS-HELLAUER, T. What is open peer review?: a systematic review. F1000 Research: Open for Science, Rockville, v. 6, n. 5888, p. 1-30, Oct. 2017. Disponível em:

https://f1000research.com/articles/6-

588\#: :text=Whereas\%20in\%20traditional\%20peer\%20review,structured\%20reviews\%20or \%20shorter\%20comments. Acesso em: 12 jul. 2021.

ROSS-HELLAUER, T.; DEPPE, A; SCHMIDT, B. Survey on open peer review: attitudes and experience amongst editors, authors, and reviewers. Plos One,San Francisco, p. 1-28, Dec. 2017. Disponível em: https://journals.plos.org/plosone/article?id=10.1371/journal. pone.0189311. Acesso em: 20 jun. 2021.

SILVA, K. L. N.; GARCIA, J. C. R.; TARGINO, M. G. Open peer review: dimensões teóricas e metodológicas. In: ZAFAON, Z. R. et al. (Org.). Percursos de Pesquisa em Ciência da Informação: produção cientifica e discussões teórico-conceituais. São Paulo: ABECIN, 2021. Cap. 39.

SHINTAKU, M.; SALES, L. Ciência aberta para editores científicos. São Paulo: ABEC, 2019.

SMITH, R. Abrindo a revisão por pares do BMJ: um começo que deve levar à total transparência. TheBMJ. 318 (7175) Jan. 1999. Disponível em:

https://www.ncbi.nlm.nih.gov/pmc/articles/PMC1114535/. Acesso em jan. 2022.

SPINAK, E. O que é esse tema de preprints? Blog Scielo em Perspectiva,São Paulo, nov. 2016. Disponível em: https://blog.scielo.org/blog/2016/11/22/o-que-e-este-tema-dospreprints/\#.YeQYH_7MKMo. Acesso em: 10 ago. 2021.

TENNANT, J. P. et al. Uma perspectiva multidisciplinar sobre inovações emergentes e futuras na revisão por pares. F1000 Research: Open for Science, Rockville, v. 6, n. 1151, p. 2-58, Aug. 2017. Disponível em: https://f1000research.com/articles/6-1151/v1. Acesso em: 13 ago. 2021. 